\title{
Preliminary Aerodynamic Design Methodology for Aero Engine Lean Direct Injection Combustors
}

Jie Li

lisasy2014@hotmail.com

AECC Shenyang Engine Research Institute

Shenyang, Liaoning

China

Xiaoxiao Sun, Yize Liu and Vishal Sethi

x.sun@cranfield.ac.uk

Centre for Propulsion Engineering

School of Aerospace, Transport and Manufacturing

Cranfield University, Bedfordshire

UK

\begin{abstract}
The Lean Direct Injection (LDI) combustor is one of the low emissions combustors with great potential in aeroengine applications, especially those with high overall pressure ratio. A preliminary design tool providing basic combustor sizing information and qualitative assessment of performance and emission characteristics of the LDI combustor within a short period of time will be of great value to designers. In this research, the methodology of preliminary aerodynamic design for a second generation LDI (LDI-2) combustor was explored. A computer code was developed based on this method covering the design of air distribution, combustor sizing, the diffuser, dilution holes and swirlers. The NASA correlations for NOx emissions are also embedded in the program in order to estimate the NOx production of the designed LDI combustor. A case study was carried out through the design of an LDI-2 combustor named as CULDI2015 and the comparison with an existing RQL combustor operating at identical conditions. It is discovered that the LDI combustor could potentially achieve a reduction in liner length and NOx emissions by $18 \%$ and $67 \%$ respectively. A sensitivity study on parameters such as equivalence ratio, dome and passage velocity and fuel staging is performed to investigate the effect of design uncertainties on both preliminary design results and NOx production. A summary on the variation of design parameters and their impact is presented. The developed tool is proved to be valuable to preliminarily evaluate the LDI combustor performance and NOx emission at the early design stage.
\end{abstract}

Keywords: LDI; preliminary design; NOx emission 


\section{NOMENCLATURE}

\section{Abbreviations}

BPR

CAEP

CFD

FAR

ICAO

LDI

LPP

LTO

MLDI

NASA

RQL

SFC

SMD

TAPS

TRL

Bypass Ratio

Committee on Aviation Environmental Protection

Computational Fluid Dynamics

Fuel-air-ratio

International Civil Aviation Organization

Lean Direct Injection

Lean-Burn Premix Prevaporized

Landing and Take-off

Multi-Point Lean Direct Injection

National Aeronautics and Space Administration

Rich-Burn, Quick-Quench, Lean-Burn

Specific Fuel Consumption (kg fuel/s kN)

Sauter Mean Diameter

Twin Annular Premixing Swirler

Technology readiness levels

\section{Notations}

$\begin{array}{ll}\text { A } & \text { Area }\left(\mathrm{m}^{2)}\right. \\ \mathrm{AR} & \text { Area Ratio } \\ \mathrm{C}_{\mathrm{p}} & \text { Real Pressure Recovery Coefficient } \\ \mathrm{C}_{\mathrm{pi}} & \text { Ideal Pressure Recovery Coefficient } \\ \mathrm{D} & \text { Diameter }(\mathrm{m}) \\ \mathrm{D}_{\mathrm{p}} & \text { The Mass of Any Gaseous Pollutant Emitted During the } \\ & \text { Reference Emissions Landing and Take-off Cycle }(\mathrm{g}) \\ \mathrm{EI} & \text { Emission Index (g/kg of fuel) } \\ \mathrm{F}_{00} & \text { Rated Thrust of the Engine }(\mathrm{kN}) \\ \mathrm{G}_{\mathrm{m}} & \text { Axial Flux of Angular Momentum } \\ \mathrm{G}_{\mathrm{t}} & \text { Axial Thrust } \\ \mathrm{HE} & \text { Height (m) } \\ \mathrm{J} & \text { Momentum-flux Ratio } \\ \mathrm{K} & \text { Swirler Coefficient } \\ \mathrm{LW} & \text { Length to Width Ratio } \\ \mathrm{M} & \text { Mach Number } \\ \mathrm{N}, \mathrm{n} & \text { Number } \\ \mathrm{NOx} & \text { Nitrogen Oxides } \\ \mathrm{P} & \text { Total Pressure (kPa) } \\ \mathrm{PR} & \text { Pressure Ratio } \\ \mathrm{S}_{\mathrm{N}} & \text { Swirl Number } \\ \mathrm{T} & \text { Total Temperature }(\mathrm{K}) \\ \mathrm{TET} & \text { Turbine Entry Temperature }(\mathrm{K}) \\ \mathrm{V} & \text { Velocity (m/s) } \\ \mathrm{W} & \text { Mass Flow (kg/s) } \\ \mathrm{Y} & \text { Penetration of Jets (m) } \\ \Delta \mathrm{P} / \mathrm{P} & \text { Pressure Loss } \\ \eta & \text { Combustion Efficiency } \\ \Phi & \text { Equivalence Ratio } \\ \varepsilon & \text { Cooling Effectiveness } \\ \mu & \text { Fraction of Air } \\ \gamma & \text { Isentropic Coefficient } \\ \rho & \text { Density (kg/m }{ }^{3} \text { ) } \\ \theta & \\ & \text { Diffuser Divergence Half Angle }\left({ }^{\circ}\right) \\ & \end{array}$

\section{Subscripts}

Combustor Inlet 


$\begin{array}{ll}4 & \text { Combustor Outlet } \\ \mathrm{a} & \text { Air } \\ \mathrm{at} & \text { Atomizing } \\ \mathrm{b} & \text { Burn } \\ \mathrm{c} & \text { Coolant, Cooling } \\ \mathrm{d} & \text { Dome } \\ \mathrm{dc} & \text { Dome Cooling } \\ \mathrm{dd} & \text { Dump Diffuser } \\ \text { dif } & \text { Diffuser } \\ \text { dil } & \text { Dilution } \\ \text { dil-cs } & \text { Cross Section of Dilution Holes } \\ \mathrm{f} & \text { Fuel } \\ \mathrm{g} & \text { Gas } \\ \text { hub } & \text { Swirler Hub } \\ \mathrm{j} & \text { Jet } \\ \mathrm{L} & \text { Liner } \\ \mathrm{lc} & \text { Liner Cooling } \\ \mathrm{lcpz} & \text { Liner Cooling in Primary Zone } \\ \mathrm{m} & \text { Metal } \\ \mathrm{m} 1,2,3 & \text { Injector main1, main2 and main3 } \\ \mathrm{p} & \text { Passage } \\ \text { pd } & \text { Pre-diffuser } \\ \text { pilot } & \text { Pilot Injector } \\ \text { pitch } & \text { Pitch Point } \\ \text { pj } & \text { Primary Jets } \\ \text { pz } & \text { Primary Zone } \\ \text { ref } & \text { Reference } \\ \text { stoi } & \text { Stoichiometric Condition } \\ \text { sw } & \text { Swirler } \\ \text { wind } & \text { Windmilling Condition } \\ & \end{array}$

\subsection{INTRODUCTION}

In the past four decades, more stringent regulations on aircraft NOx emission during LTO (landing and take-off) cycle have been imposed by the International Civil Aviation Organization (ICAO) due to its effect on the local air quality at low altitude [1]. Another potential damage of NOx to the environment is its influence on the ozone layer depletion during cruise at high altitude are also although no legislations have been applied so far. Meanwhile, the continuous elevation in engine overall pressure ratio and turbine entry temperature (TET) due to performance requirements further contribute to the formation of NOx. Combustors which not only satisfy ICAO LTO NOx emissions regulations but are also able to achieve high efficiency and low Specific Fuel Consumption (SFC) are in high demand. Low emission technologies such as Rich-burn Quick-quench Lean-burn (RQL) have been developed and proved successful. The LDI is one of the concepts which utilises lean combustion to limit NOx formation by lowering the flame temperature. Compared to other low emission combustors, the LDI is shorter in length and capable of achieving further reduction in NOx relative to RQL combustor. It is less likely to suffer from combustion instabilities and flashback than the Lean Premixed Prevaporized (LPP) combustor. However, current research including those by NASA and Rolls-Royce have only reached TRL up to 6 and 4 respectively [2,3]. Neither in-service engine applications have been achieved, nor design methodologies have been published. Another lean burn combustor named as TAPS (Twin Annular Premixing Swirler) has reached TRL9 and applied on GEnx engines for Boeing B747-8 and B787 since 2011. It incorporates a pilot stage with diffusion flame and partially premixed main stage injectors positioned radially outwardly of the pilot. However detailed reviews and comparisons between these technologies are beyond the scope of this paper as it mainly focuses on the design methodology of a NASA LDI-2 combustor, more references on TAPS combustor could be found in $[1,4]$. CFD is widely used throughout the combustor design process, while its consumption in time and computational power may not be affordable or economical at the early design stage where limited information is available. The need is clear for the development of the LDI combustor design method which provides the best compromise between time and accuracy as well as useful information for higher fidelity simulations.

The LDI combustor takes advantage of lean combustion, the flame temperature of which is decreased by burning the fuel away from the stoichiometric condition. Instead of being prevaporized and premixed with air, the fuel is directly injected into the flame zone. Hence LDI combustors are less prone to auto-ignition and 
flashback than LPP combustors. The fuel injector design is therefore critical for LDI combustors since good atomization and homogeneous fuel-air mixing should be guaranteed.

Two types of LDI combustors have been developed, Rolls-Royces LDI [5] and NASA Multi-point LDI (MLDI) concept [6]. The RR LDI is similar to the TAPS concept, which features an internally staged SAC architecture. The centre pilot and surrounding main stages are separated by a splitter which creates a wake called bifurcated flow field leading to the separated pilot and main flame. The RR LDI combustor is reported to demonstrate a NOx reduction of $60 \%$ against the CAEP/6 at TRL6 for an engine with pressure ratio of 39 . Unlike the concept of the RR LDI having a larger fuel injector, the idea of the NASA MLDI is to divide the combustor dome into arrays of small injectors in order to achieve uniform fuel air mixing across the dome area. There are two generations of MLDI combustors, namely LDI-1 and LDI-2. The dome of the LDI-1 is composed of many identical fuel-injectors whereas fuel-staging is applied in the structure of LDI-2 injectors, which allows the attainment of further reduction of NOx and wider operating range. The LDI-2 can be further categorized into 3 concepts developed by Parker Hannifin Corporation, Goodrich Corporation and Woodward FST respectively. The LDI-2 Woodward concept is selected for this study since it has better operability at low power settings than the LDI-1. The number of injectors is also smaller compared to other concepts therefore reducing the complexity and cost of the system. The dome of a flat dome LDI-2 Woodward combustor is shown in Figure 1. A large pilot injector is located in the centre of the matrix, surrounded by main injectors named as main1, main2, and main3. Each of the main injectors has 4 identical configurations. Table 1 provides details on fuel injectors and swirlers. The fuel stage zones are fed by 3 fuel lines with main 2 and main 3 sharing the same supply. Up to $87-88 \%$ reduction from CAEP/6 standard can be achieved according to the experiment with Woodward's configuration [7]. The fuel and air staging at different power settings are apparently critical to the performance and emission of the LDI-2 combustor, which is the focus of this paper.

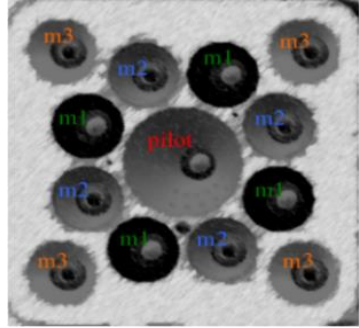

Figure 1 LDI-2 combustion concept (Woodward) [7]

Table 1

Second generation of NASA MLDI configurations by Woodward FST [7]

\begin{tabular}{|c|c|c|c|}
\hline $\begin{array}{c}\text { Pilot } \\
\text { Injector }\end{array}$ & $\begin{array}{c}\text { Pilot } \\
\text { Swirler }\end{array}$ & $\begin{array}{c}\text { Main1 } \\
\text { Injector }\end{array}$ & $\begin{array}{c}\text { Main1 } \\
\text { Swirler }\end{array}$ \\
\hline Simplex & $55^{\circ} \mathrm{ccw}$ & Simplex & $45^{\circ} \mathrm{ccw}$ \\
\hline Main2 & $\begin{array}{l}\text { Main2 } \\
\text { Swirler }\end{array}$ & Main3 & $\begin{array}{l}\text { Main3 } \\
\text { Swirler }\end{array}$ \\
\hline Airblast & $\begin{array}{l}\text { IAS: } 45^{\circ} \mathrm{cw} \\
\text { OAS: } 45^{\circ} \mathrm{cw}\end{array}$ & Airblast & $\begin{array}{l}\text { IAS: } 45^{\circ} \mathrm{cw} \\
\text { OAS: } 45^{\circ} \mathrm{cw}\end{array}$ \\
\hline
\end{tabular}

\subsection{METHODOLOGY}

At the early stage of the combustor design, the procedure usually follows the routine shown in Figure 2. Given the combustor inlet and outlet conditions along with the architecture as the input, the amount of air partitioned into each zone is then determined. The size of the combustor and its components is calculated based on air partitioning. Although not included in the current research, the fuel injection system must also be developed to provide information such as spray cone angle and Sauter Mean Diameter (SMD). It is noteworthy that some of the correlations applied in this paper may be outdated due to limited information in the public domain and should be treated with caution. Specific notes will be addressed when these correlations are used.

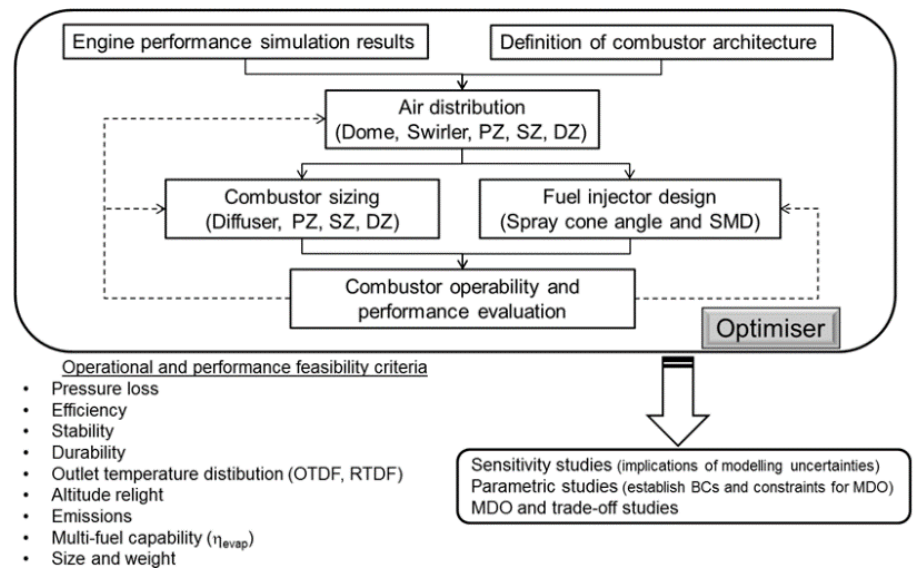

Figure 2 Combustor preliminary design procedure 
The preliminary design is evaluated by various operational and performance criteria and adjusted according to evaluation feedback. Sensitivity studies are conducted investigating design and model uncertainties. The preliminary design results can be optimised by employing Multi-Disciplinary Design Optimisation (MDO) to further fulfil the often-conflicting requirements. As more requirements such as cooling, stability and size are met during the development and optimisation, the emission performance will be compromised. Consequently, the emission production increases for more matured technologies with higher TRL.

\section{$2.1 \quad$ Assumptions}

For this study, Jet-A with a chemical formula of $\mathrm{C}_{12} \mathrm{H}_{23.5}$ is selected as the fuel. Constant gas properties are applied to simplify the preliminary design process. The difference between the constant and variable gas properties on the design outcome is discussed in the sensitivity study. The flow coefficient is assumed to be unity for the design of liner holes and swirlers.

\subsection{Air distribution}

The configuration of an LDI combustor differs from that of a conventional combustor, thus the air distribution method of Mellor [8] and Mattingly [9] were combined along with specific consideration for LDI combustors. In an LDI combustor, only the primary and dilution zones exist; primary holes are cancelled, making a majority of the air entering from the dome.

The equivalence ratio of the primary zone is firstly determined. To calculate the flame temperature, Mattingly's [9] method is no longer suitable for $\Phi$ above unity. Walsh and Fletcher's [10] correlations summarizing a large amount of experimental data on kerosene are applied. They are expressed as follows:

$$
\begin{gathered}
F A R_{1}=0.10118+2.00376 * 10^{-5} *\left(700-T_{3}\right) \\
F A R_{2}=23.7078 * 10^{-3}-5.2368 * 10^{-6} *\left(700-T_{3}\right)-5.2632 * 10^{-6} * T_{g} \\
F A R_{3}=8.889 * 10^{-8} *\left|T_{g}-950\right| \\
F A R=\left(F A R_{1}-\sqrt{F A R_{1}^{2}+F A R_{2}}-F A R_{3}\right) / \eta_{b}
\end{gathered}
$$

The flame temperature can be derived from the equations above with several iterative calculations. A correction coefficient FAR $_{\text {stoi }} / F A R$ is applied in the gas temperature if FAR exceeds FAR $_{\text {stoi }}$. The liner cooling air partitioning is calculated by Mattingly's method with cooling effectiveness and the fraction of cooling air required defined as

$$
\begin{array}{cc}
\varepsilon=\frac{T_{g}-T_{m}}{T_{g}-T_{c}} & (5) \\
\mu_{c}=\frac{\varepsilon}{25 *(1-\varepsilon)} & \text { transpiration/effusion cooling }
\end{array}
$$

Where $T_{g}, T_{m}$ and $T_{c}$ are the temperature of the hot gas, liner metal and the coolant respectively. For an LDI combustor, more effective cooling techniques should be employed such as effusion and transpiration cooling since more air is supplied to sustain lean combustion. The amount of cooling air in primary and dilution zones is assumed to be equivalent. The total amount of air in the primary zone is the sum of the dome air and the cooling air in the primary zone. Therefore, the dome air which consists of swirler air and dome cooling air can be calculated. Referring to Mellor [8], the dome cooling air is chosen within a range of 10-15\% of the total air flow. The remaining air is then regarded as the dilution air.

\subsection{Sizing}

The velocity method was chosen to determine reference parameters of the combustor and theta parameter method was utilized to verify if the design is satisfactory at windmilling conditions (altitude relight capability). Typical values of dome and passage velocities are shown in Table 2.

Table 2

Typical dome and passage reference velocities [8]

$\begin{array}{ccc}\text { Velocity }(\mathbf{m} / \mathbf{s}) & \text { Nominal value } & \text { Range } \\ \text { Dome } & 9 & 7-12 \\ \text { Passage } & 50 & 35-60\end{array}$

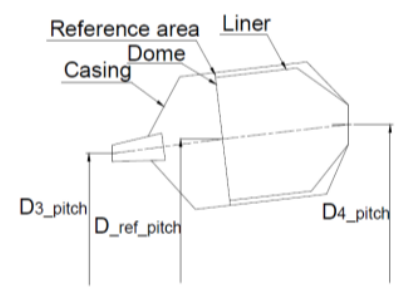

Figure 3 Sketch of the combustor 
They can be slightly adjusted for the LDI combustor in order to satisfy performance and size requirement. The dome and passage area $A_{d}$ and $A_{p}$ can then be calculated by

$$
\begin{aligned}
& A_{d}=\frac{W_{d}}{\rho_{3} V_{d}} \\
& A_{p}=\frac{W_{p}}{\rho_{3} V_{p}}
\end{aligned}
$$

Where $W_{d}$ and $V_{d}$ represents the air mass flow and velocity entering to the dome and combustor inlet density $\rho_{3}$. The reference area $\mathrm{A}_{\text {ref, }}$, which is the sum of the dome and passage area, is calculated so that the reference velocity $\mathrm{V}_{\text {ref }}$ is obtained.

$$
\begin{array}{ll}
A_{\text {ref }}=A_{d}+A_{p} & (9) \\
V_{\text {ref }}=\frac{W_{3}}{\rho_{3} A_{\text {ref }}} & (10)
\end{array}
$$

The calculation and verification of theta parameters at windmilling condition are identical with that described in Zhao [11], where the theta parameter curve for conventional combustors with stoichiometric primary zone is employed due to lack of data for RQL combustors. According to the theta curve in Ref [12] (see Figure 4), for lean primary zone combustors, lower combustion efficiency is expected for the same value of theta when compared with conventional combustors. The calculated combustion efficiency for LDI combustor in this study could be over predicted.

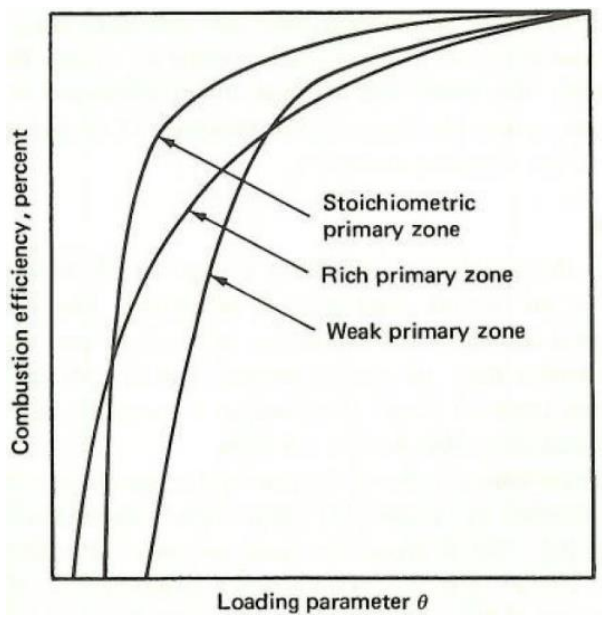

Figure 4 Effect of primary zone mixture strength on the shape of theta curves [12]

As illustrated in Figure 3, the diameter of the pitch point of the reference cross section $\mathrm{D}_{\text {ref_pitch }}$ can be roughly estimated as $0.5\left(\mathrm{D}_{3_{\text {_p }} \text { itch }}+\mathrm{D}_{4 \_ \text {pitch }}\right)$. The reference and dome heights can then be determined by

$$
\begin{gathered}
H E_{\text {ref }}=\frac{A_{\text {ref }}}{\pi D_{\text {ref_pitch }}} \\
H E_{\text {dome }}=\frac{A_{\text {dome }}}{\pi D_{\text {ref_pitch }}}
\end{gathered}
$$

The combustor liner length should be designed to optimise combustion efficiency and overall weight. The suggested length for a conventional combustor is twice that of the dome height, which is not appropriate since the dome area for LDI combustors is larger due to extra air for lean combustion. It is reasonable to assume that the liner length is equal to the dome height. The number of combustor domes is estimated by

$$
N_{d}=\frac{\pi D_{\text {ref_pitch }}}{H E_{\text {ref }}}
$$




\subsection{Diffuser}

The diffuser of a modern annular combustor is normally composed of a faired pre-diffuser followed by a dumpdiffuser for the purpose of reducing air velocity and achieving stable combustion with limited length and pressure loss, commonly 4-6\%. This combination is selected for the design of the LDI combustor. The design method used by Mohanmmad and Jeng [13] is applied. The area ratio AR, which is the ratio between the area of the outlet and the inlet of the pre-diffuser (A2/A1), ranges between 1.4 and 3.0. The length to width ratio can be expressed as follows:

$$
\begin{array}{ll}
L W=\left(\frac{A R}{1.044}\right)^{\frac{1}{0.38859}}-0.26 & (A R<2) \\
L W=\frac{44.8535}{1+2165.67 e^{-2.8225 A R}} \quad(A R>2) & (14)
\end{array}
$$

The pre-diffuser divergence half angle $\theta$ is represented by Eq. 16 and within the range of $4-8^{\circ}$.

$$
\tan \theta=\frac{A R-1}{2 L W}
$$

The ideal and the real pressure recovery coefficient are dependent on AR and LW

$$
\begin{gathered}
C_{p i}=1-\left(\frac{1}{A R^{2}}\right) \\
C_{p}=-0.918 * \frac{1}{A R^{0.5} * L W}+0.677 * \frac{1}{A R^{2} * L W^{2}}+0.74
\end{gathered}
$$

The pressure loss for both the pre-diffuser and the dump diffuser are formulated as

$$
\begin{gathered}
\frac{\Delta P_{p d}}{P_{3}}=\left(C_{p i}-C_{p}\right)\left[1-\left(1+\frac{\gamma-1}{2} M_{31}^{2}\right)^{\frac{-\gamma}{\gamma-1}}\right] \\
\frac{\Delta P_{d d}}{P_{3}}=\left[1-\left(\frac{A_{1}}{A_{\text {ref }}} * A R\right)^{2}\right]\left[1-\left(1+\frac{\gamma-1}{2} \frac{M_{31}^{2}}{A R^{2}}\right)^{\frac{-\gamma}{\gamma-1}}\right]
\end{gathered}
$$

The total pressure loss of the diffuser is calculated by

$$
\frac{\Delta P_{d i f}}{P_{3}}=1-\left(1-\frac{\Delta P_{p d}}{P_{3}}\right)\left(1-\frac{\Delta P_{d d}}{P_{3}}\right)
$$

\subsection{Dilution holes}

The dilution holes enable the injection of the dilution air to further complete the combustion and tailor the outlet temperature profile. The jet penetration should be sufficient for good mixing in order to produce reasonable RTDF while not extravagant to limit pressure loss. The number and size of the dilution holes can be estimated by the method described in this section. Due to the lack of more recent materials in the calculation of dilution holes, the current method only provides an indicative analysis as it was developed for technologies decades ago. More research should be conducted to obtain correlations or models applicable to low emissions combustors.

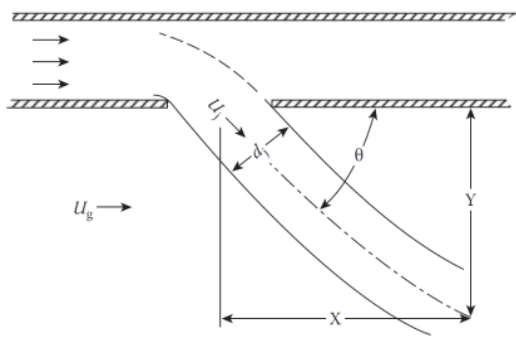

Figure 5 Sketch of flow through liner hole [14]

As shown in Figure 5, the flow through the liner hole can be described by several parameters. To simplify the design, the jet angle $\theta$ is assumed to be $90^{\circ}$. 
According to Lefebvre [14], the penetration of multiple jets can be estimated by

$$
Y_{\max }=1.25 D_{j} J^{0.5} \frac{W_{g}}{W_{g}+W_{j}}
$$

With $\mathrm{W}_{\mathrm{g}}$ and $\mathrm{W}_{\mathrm{j}}$ being the mass flow rate of the hot gas and cooling jet, and

$$
J=\frac{\rho_{j} V_{j}^{2}}{\rho_{g} V_{g}^{2}}
$$

The Cranfield Design Method [14] which reveals the influence of the aerodynamic blockage caused by jets on the penetration and mixing process is utilized to obtain the optimum hole number and size. It is suitable for cases with an extremely high value of $\mathrm{W}_{\mathrm{j}} / \mathrm{W}_{\mathrm{g}}$. The mass flow rate of the air through the dilution holes is

$$
W_{j}=\frac{\pi}{4} n D_{j}^{2} \rho_{3} V_{j}
$$

Where the jet velocity $\mathrm{V}_{\mathrm{j}}$ can be obtained by

$$
V_{j}=\left(\frac{2 \Delta P_{L}}{\rho_{3}}\right)^{0.5}
$$

The number and the diameter of the holes can be represented by

$$
n D_{j}^{2}=15.25 W_{j}\left(\frac{P_{3} \Delta P_{L}}{T_{3}}\right)^{-0.5}
$$

The liner pressure loss can be calculated by subtracting the diffuser pressure loss and hot combustion loss from the specified pressure loss through the combustor. The momentum-flux ratio $\mathrm{J}$ should be within the range of 5105 [8]. According to Lefebvre [14], it is suggested that for annular combustors, the jet penetration is close to $0.4 \mathrm{HE}_{\mathrm{d}}$, hence the diameter and the number of the dilution holes are obtained.

\subsection{Swirler}

The axial swirler is selected in the research of LDI-2 combustor concept. Therefore, it is chosen for the LDI combustor design in this paper. Both flat-vaned and curved-vaned have been used in the research of LDI combustors because of their different advantages. In this paper, the flat vane is chosen for its simplicity and low cost. The design parameters of an axial swirler are shown in Figure 6.

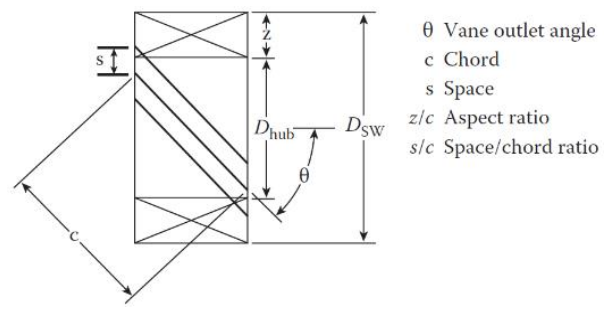

Figure 6 Definition of axial swirler [14]
Table 3

Typical values of axial swirler design [14]

$\begin{array}{ll}\text { Parameter } & \text { Range } \\ \text { Vane angle, } \boldsymbol{\theta} & 30^{\circ}-60^{\circ} \\ \text { Vane thickness, } \mathbf{t}_{\mathbf{v}} & 0.7-1.5 \mathrm{~mm} \\ \text { Number of vanes, } \mathbf{n}_{\mathbf{v}} & 8-16 \\ \boldsymbol{\Delta}_{\mathbf{s w}} & 3-4 \% \text { of } \mathrm{P}_{3} \\ \mathbf{K}_{\mathbf{s w}} & 1.3 \text { for flat vanes }\end{array}$

The calculation is carried out using the following equations:

$$
\begin{gathered}
W_{s w}=\sqrt{\frac{2 \rho_{3} \Delta P_{s w}}{K_{s w}\left[\left(\frac{\sec \theta}{A_{s w}}\right)^{2}-\frac{1}{A_{L}^{2}}\right]}} \\
A_{s w}=\frac{\pi}{4}\left(D_{s w}^{2}-D_{h u b}^{2}\right)-0.5 n_{v} t_{v}\left(D_{s w}-D_{h u b}\right)
\end{gathered}
$$

The swirler pressure loss $\Delta \mathrm{P}_{\mathrm{sw}}$ is assumed to be equal to the liner pressure loss. The vane angle $\theta$ is constant for the flat-vaned swirler. The typical values of these parameters are listed in Table 3 . The value of $D_{\text {hub }}$ is usually slightly larger than the outer diameter of the fuel injector for installation consideration. $\mathrm{D}_{\mathrm{sw}}$ can be determined based on the information above.

According to Beer and Chigier [15], the swirler strength is characterized by the swirl number defined in Eq. 29. 


$$
S_{N}=\frac{2 G_{m}}{D_{s w} G_{t}}
$$

Where $G_{m}$ is the axial flux of the angular momentum and $G_{t}$ is the axial thrust. For a flat-vaned swirler, the swirl number can be simplified as represented in Eq. $30[14,15]$ due to difficulties in measuring angular momentum and axial thrust.

$$
S_{N}=\frac{2\left(1-\left(\frac{D_{h u b}}{D_{s w}}\right)^{3}\right)}{3\left(1-\left(\frac{D_{h u b}}{D_{s w}}\right)^{2}\right)} \tan \theta
$$

In practical cases, $S_{n}$ mainly ranges from 0.6-1.5 to generate steady recirculation and prevent the reverse mass flow exceeding the swirler mass flow [16]. For LDI combustors, good mixing is essential for the reduction of NOx, which requires a swirl number around 0.8-1.0 [17, 18, 19, 20]. In this paper, the swirl number is restricted within 0.6-1.2.

The rotation orientation of adjacent swirlers is another critical factor influencing the mixing process of the LDI combustor, since it contains hundreds of injectors, the essential elements of which are swirlers. In summary of Yang [21], Cai [19, 22] and Fu's [20, 23] study, the counter-swirler tends to have better performance and greater turbulence than the co-swirler. It has also been applied in the LDI-2 combustion concept research, therefore is selected here. Finally, the total dimension of the swirlers should not exceed the combustor dome height to prevent installation difficulties.

\subsection{Fuel staging}

For LDI combustors, only the pilot stage operates at ground idle condition. As the power setting increases, the main 1 stage participates in the combustion for the approach condition. During climb and take-off, all stages are lit. The local equivalence ratio can be defined as Eq. 31 with a representing the fraction of the dome cooling air distributed to each stage.

$$
\text { local } \Phi=\frac{W_{f}}{W_{s w}+a W_{d c}}
$$

The equivalence ratio at the pilot stage is decided first. The main function of the pilot stage is to stabilize the flame at low power setting. On the one hand, the equivalence ratio at the pilot stage is designed to be above unity to secure sufficient air for main stages and to avoid stoichiometric combustion where the flame temperature is so high that the formation of thermal NOx nears peak value. On the other hand, substantial smoke and even rich extinction could appear as the equivalence ratio continues to rise. A value between 1.2 and 1.6 is recommended although it could reach 2.4 in LDI-2 Goodrich concept test. A sensitivity study was carried out and is presented in Section 4. The fuel staging for main stage injectors is determined afterwards. Caution should be taken that the equivalence ratio at each main stage should be similar [24] so that homogeneous mixing and combustion can be achieved to prevent local hot spot where a large amount of thermal NOx is likely to be produced. The possibility of weak extinction due to the excessive amount of air should also be eliminated during the calculation.

\subsection{NOx correlations for LDI combustors}

Tacina et al. [7] developed correlations predicting NOx emission for second generation LDI combustors with flat dome, which is the type used in this study. They were based on tests in a flame tube conducted by NASA Glenn Research Centre. It can be seen from Eq. 32 that the emission mainly depends on inlet pressure and temperature, pressure loss and equivalence ratio.

$$
\text { EINOX }=P_{3}^{0.50} e^{\frac{T_{3}}{230}}\left(\frac{\Delta P}{P_{3}}\right)^{-0.60}\left(0.0081 \Phi_{\text {pilot }}^{0.29}+0.350 \Phi_{m 1}^{7.15}+0.369 \Phi_{m 2,3}^{7.37}\right) \quad \quad(\quad 32 \quad)
$$

For the purpose of comparison, the EINOx of the LDI-1 combustor is also calculated by the correlation proposed by Tacina et al. [17] multipoint LDI-1 combustors as shown in Eq. 33, which could be applied to both high and medium pressure situations.

$$
\text { EINOX }=1.359 e^{\frac{T_{3}}{194}} F A R^{1.69} P_{3}^{0.595}\left(\frac{\Delta P}{P_{3}}\right)^{-0.565}
$$




\subsection{Code structure}

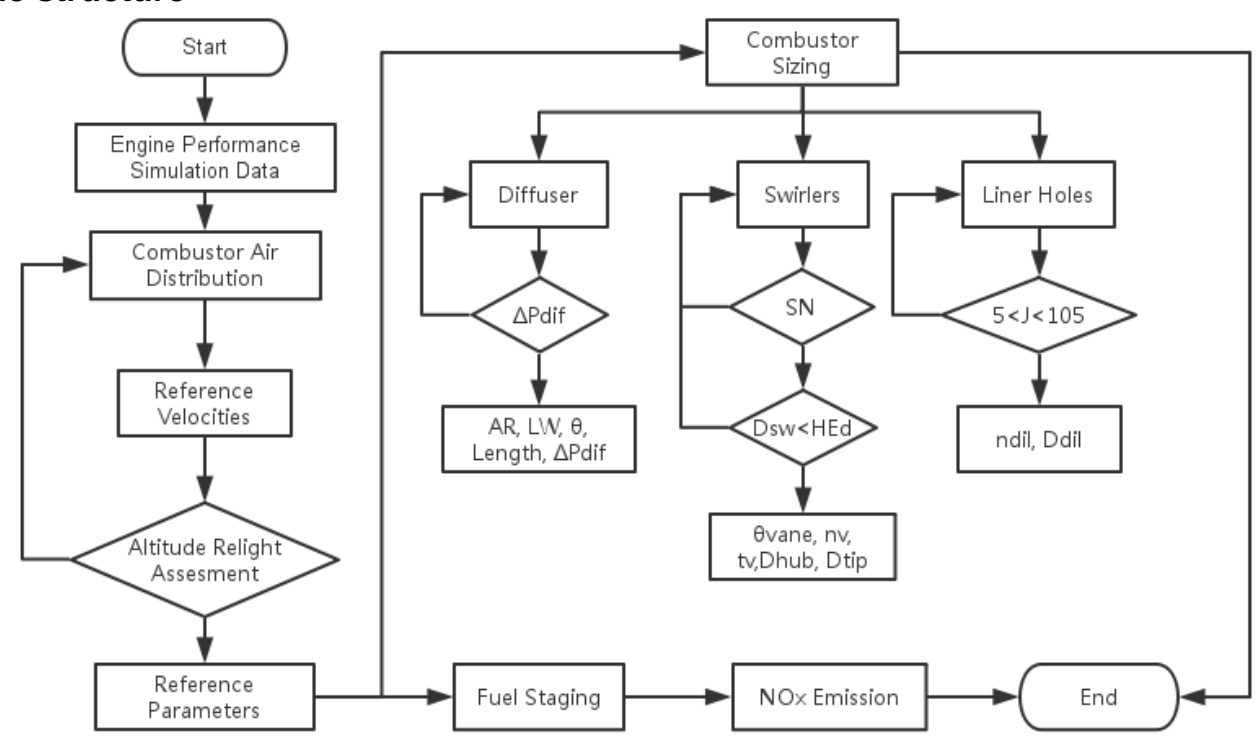

Figure 7 LDI combustor design codes flow chart

\subsection{CASE STUDY}

The preliminary aerodynamic design of an LDI-2 Woodward's concept combustor, namely CULDI2015, was conducted for an engine similar to V2500 renamed as CUTF1. The design outcome is analysed and compared with the V2500 RQL combustor since its structure dimensions and boundary conditions have been used as the input for the CULDI2015 combustor (listed in Table 4 and Table 5). The combustor geometric sizes were measured from figures in [25], while the inlet and outlet conditions at different power settings were obtained from the in-house Cranfield University gas turbine performance simulation tool TURBOMATCH, which have been validated against available data [11].

Table 4

Input structure dimensions

$\begin{array}{lllll}\text { Parameter } & \text { D)_pitch } & \text { D4_pitch } & \text { Dref_pitch } & \text { A2 } \\ \text { Unit } & \mathrm{m} & \mathrm{m} & \mathrm{m} & \mathrm{m} \\ \text { Value } & 0.508 & 0.582 & 0.545 & 2.043\end{array}$

Table 5

Codes input parameters for LTO cycle

$\begin{array}{llllll}\text { Parameter } & \text { Unit } & \text { T/O (DP) } & \text { Climb } & \text { Approach } & \text { Ground idle } \\ \text { PR } & - & 32.7 & 29.4 & 15.6 & 6.7 \\ \text { BPR } & - & 5.0 & 5.0 & 5.0 & 5.0 \\ \text { TET } & \mathrm{K} & 1728 & 1647 & 1326 & 1034 \\ \mathbf{P}_{\mathbf{3}} & \mathrm{kPa} & 3317 & 2983 & 1579 & 678 \\ \mathbf{T}_{\mathbf{3}} & \mathrm{K} & 849 & 821 & 692 & 554 \\ \mathbf{W}_{\mathbf{3 1}} & \mathrm{kg} / \mathrm{s} & 51.19 & 47.18 & 28.03 & 13.83 \\ \mathbf{W}_{\mathbf{f}} & \mathrm{kg} / \mathrm{s} & 1.36 & 1.16 & 0.50 & 0.18\end{array}$

The primary zone equivalence ratio is firstly selected with a value of 0.5 , leading to a calculated flame temperature of $1820 \mathrm{~K}$. Such flame temperature sits within the range from $1670 \mathrm{~K}$ to $1900 \mathrm{~K}$, where both CO and NOx emissions are limited. Besides, a flame temperature of $1820 \mathrm{~K}$ is appropriate for an engine with an overall pressure ratio of 32.74. It can be concluded that the primary zone equivalence ratio is reasonable. Table 6 presents the air distribution in each zone and stage of the LDI combustor. The fraction of the liner cooling air is calculated using Eq. 5, 6 with the assumption that the maximum liner temperature does not exceed $1100 \mathrm{~K}$. It can be seen that in the designed LDI combustor, $77.9 \%$ of the total air mass flow is contained in the primary zone, which is totally different from the case of conventional combustors. The dome cooling air takes up to $15.0 \%$ of the total air mass flow, therefore the dome area is notably larger than that of a conventional combustor. 
Table 6

Combustor air distribution

$\begin{array}{lllllllll}\text { Mass flow } & \mathbf{W}_{\mathbf{p z}} & \mathbf{W}_{\mathbf{d}} & \mathbf{W}_{\text {pilot }} & \mathbf{W}_{\mathbf{m} 1} & \mathbf{W}_{\mathbf{m} 2,3} & \mathbf{W}_{\text {dc }} & \mathbf{W}_{\text {lc }} & \mathbf{W}_{\text {dil }} \\ \text { Value (kg/s) } & 39.89 & 36.95 & 4.26 & 8.34 & 16.67 & 7.68 & 5.88 & 8.36 \\ \text { Fraction } & \boldsymbol{\mu}_{\mathbf{p z}} & \boldsymbol{\mu}_{\mathbf{d}} & \boldsymbol{\mu}_{\text {pilot }} & \boldsymbol{\mu}_{\mathbf{m} 1} & \boldsymbol{\mu}_{\mathbf{m} 2,3} & \boldsymbol{\mu}_{\text {dc }} & \boldsymbol{\mu}_{\mathbf{l c}} & \boldsymbol{\mu}_{\text {dil }} \\ \text { Value } & 0.779 & 0.722 & 0.083 & 0.163 & 0.326 & 0.150 & 0.115 & 0.163 \\ & & & & & & & & \end{array}$

The fuel staging for the LDI combustor at each of the four power settings is carried out with the criteria aforementioned and listed in Table 7. The fuel allocated to the pilot stage is clearly decreasing as the power setting increases, from $100 \%$ at idle condition to $14.9 \%$ at maximum power. At high power settings, the fuel is staged in a way that the local equivalence ratio at each stage is similar to avoid inhomogeneous mixing.

Table 7

Fuel staging in LTO cycle

$\begin{array}{lllll}\text { Parameter } & \text { T/O(DP) } & \text { Climb } & \text { Approach } & \text { Ground idle } \\ \boldsymbol{\mu}_{\text {f_pilot }} & 0.149 & 0.161 & 0.650 & 1.000 \\ \boldsymbol{\mu}_{\text {f_m1 }} & 0.284 & 0.280 & 0.350 & 0 \\ \boldsymbol{\mu}_{\text {f_m2,3 }} & 0.567 & 0.559 & 0 & 0\end{array}$

The velocity method is used for combustor sizing. The dome and passage velocities are 10.2 and $50 \mathrm{~m} / \mathrm{s}$ respectively, which is a compromise between enhanced mixing and adequate combustor size and weight. The calculated size parameters are shown in Table 8 . It is noted that the reference velocity is $13.1 \mathrm{~m} / \mathrm{s}$, which is significantly lower than that of a conventional combustor, resulting in a larger dome area. It can be explained by the fact that the LDI combustor requires significantly more air than the conventional combustor to sustain lean combustion. The liner pressure loss is $3.29 \%$, which is acceptable for the mixing process. A liner length of $0.159 \mathrm{~m}$ is also adequate for aero-engine applications. The combustion efficiency at the windmilling condition is checked with a flight altitude of $10 \mathrm{~km}$ and a flight Mach number of 0.8 . The combustor inlet conditions are displayed in Table 9 which is evidently lower than those at the normal conditions, making it more difficult for the fuels to burn efficiently. A value of $4.11 \mathrm{e}+07$ for the theta parameter is obtained, through which the combustion efficiency is estimated above $80 \%$.

Table 8

Results of combustor sizing

$\begin{array}{llllllllll}\text { Parameter } & \mathbf{A}_{\text {ref }} & \mathbf{H E}_{\text {ref }} & \mathbf{V}_{\text {ref }} & \mathbf{A}_{\mathbf{d}} & \mathbf{H E} & \mathbf{V}_{\mathbf{d}} & \mathbf{V}_{\mathbf{p}} & \boldsymbol{\Delta} \mathbf{P}_{\mathbf{L}} / \mathbf{P}_{\mathbf{3}} & \mathbf{L}_{\mathbf{L}} \\ \text { Unit } & \mathrm{m}^{2} & \mathrm{~m} & \mathrm{~m} / \mathrm{s} & \mathrm{m}^{2} & \mathrm{~m} & \mathrm{~m} / \mathrm{s} & \mathrm{m} / \mathrm{s} & - & \mathrm{m} \\ \text { Value } & 0.293 & 0.171 & 13.1 & 0.271 & 0.159 & 10.2 & 50.0 & 3.29 \% & 0.159\end{array}$

Table 9

Combustor inlet parameters of windmilling condition

$\begin{array}{llll}\text { Parameter } & \text { P3_wind }_{3} & \text { T3_wind }_{3} & \text { W3_wind }_{3} \\ \text { Unit } & \mathrm{kPa} & \mathrm{K} & \mathrm{kg} / \mathrm{s} \\ \text { Value } & 42.2 & 261 & 0.563\end{array}$

The diffuser design outcome is shown in Table 10. The designed diffuser shows a pressure loss of $1.21 \%$, which is less than $40 \%$ of the compressor outlet velocity head as required. It is also apparent that the dump diffuser loss is the dominant factor of the diffuser pressure loss. Lower dump pressure loss could be achieved at the expense of a longer diffuser.

Table 10

Results of diffuser design

$\begin{array}{lllllllll}\text { Parameter } & \mathbf{A R} & \mathbf{L W} & \boldsymbol{\theta} & \boldsymbol{\Delta} \mathbf{P}_{\text {dif }} / \mathbf{P}_{\mathbf{3}} & \boldsymbol{\Delta} \mathbf{P}_{\mathbf{p d}} / \mathbf{P}_{\mathbf{3}} & \mathbf{\Delta} \mathbf{P}_{\mathbf{d d}} / \mathbf{P}_{\mathbf{3}} & \mathbf{L}_{\mathbf{p d}} & \mathbf{d g}_{\mathbf{g}} \\ \text { Unit } & - & - & \circ & - & - & - & \mathrm{m} & \mathrm{m} \\ \text { Value } & 1.67 & 3.09 & 6.2 & 1.21 \% & 0.28 \% & 0.93 \% & 0.065 & 0.030\end{array}$

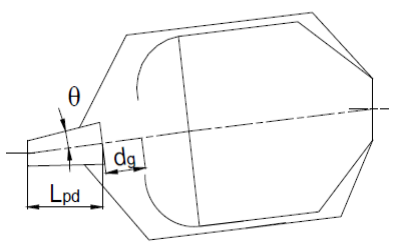


Table 11 presents the results of the dilution holes parameters determined using the Eq. 22-26 presented in Section 2.5. There are 54 holes distributed on the inner and outer liner wall, each with a diameter of $11 \mathrm{~mm}$. The cross-section area of the dilution zone is $0.192 \mathrm{~m}^{2}$, smaller than the dome area, indicating a convergent shape of the flame tube in order to achieve good turbulent mixing. The momentum-flux ratio $\mathrm{J}$ is 32.9 , which is reasonable as it lies in the suggested range of 5-105. It is demonstrated that the jet penetration and the mixing with the main stream gas are expected to be appropriate.

Table 11

Design results of combustor dilution holes

$\begin{array}{lllllll}\text { Parameter } & \mathbf{W}_{\text {dil }} & \boldsymbol{\Delta} \mathbf{P}_{\mathbf{L}} & \mathbf{n}_{\text {dil }} & \mathbf{D}_{\text {dil }} & \mathbf{A}_{\text {dil-cs }} & \mathbf{J} \\ \text { Unit } & \mathrm{kg} / \mathrm{s} & \mathrm{kPa} & - & \mathrm{m} & \mathrm{m}^{2} & - \\ \text { Value } & 41.25 & 109.2 & 54 & 0.011 & 0.192 & 32.9\end{array}$

The number of the domes for the LDI combustor is firstly estimated to be 10 with Eq. 13. Then the design of the swirlers at the pilot and each main stage is chosen to be axial swirlers, each equipped with eight $1 \mathrm{~mm}$ thick vanes. As shown in Table 1, for the pilot swirler, the vane angle is $55^{\circ}$ for the consideration of mixing and operability. The vanes in main stage swirlers are $45^{\circ}$. The design parameters of swirlers for each stage are listed in Table 12. The dimension of the entire swirler array is $88.9 \mathrm{~mm}$, which is less than the dome height. The swirl numbers are all above 0.6 , revealing sufficiently strong swirl hence good mixing.

Table 12

Results of combustor swirler design (each dome)

$\begin{array}{llllllllll}\text { Parameter } & \boldsymbol{\Delta} \mathbf{P}_{\text {sw }} & \mathbf{n}_{\text {sw }} & \mathbf{n}_{\mathbf{v}} & \mathbf{t}_{\mathbf{v}} & \boldsymbol{\theta} & \mathbf{K}_{\text {sw }} & \mathbf{D}_{\text {hub }} & \mathbf{D}_{\text {sw }} & \mathbf{S}_{\mathbf{N}} \\ \text { Unit } & \mathrm{kPa} & - & - & \mathrm{m} & \circ & - & \mathrm{m} & \mathrm{m} & - \\ \text { Pilot } & 109.2 & 1 & 8 & 0.001 & 55 & 1.3 & 0.010 & 0.029 & 1.04 \\ \text { Main1 } & 109.2 & 4 & 8 & 0.001 & 45 & 1.3 & 0.010 & 0.020 & 0.78 \\ \text { Main2,3inner } & 109.2 & 8 & 8 & 0.001 & 45 & 1.3 & 0.010 & 0.016 & 0.83 \\ \text { Main2,3 } & & & & & & \\ \text { Mater } & 109.2 & 8 & 8 & 0.001 & 45 & 1.3 & 0.016 & 0.020 & 0.90\end{array}$

Having finished the preliminary aerodynamic design of the LDI combustor, it can be observed from Figure 8 that the total length of the LDI combustor is $18 \%$ less than that of the reference RQL combustor V2500 of the current design. The reduction in length makes the LDI more competitive compared to RQL combustor if applied to a newly designed engine as reduced shaft length is beneficial to the engine rotor dynamics. However, this effect might be cancelled out by the increase in combustor diameter, which may have an impact on engine weight because of increased casing diameter. Whereas in the current design, the combustor reference sizes are slightly increased $(<10 \%)$ compared to those of the V2500 RQL combustor cited in [11] despite having a larger dome height.

As the primary interest of the LDI combustor is its relatively low NOx emissions, it is necessary to assess the NOx emission level of the designed combustor. The NOx emission correlation in Eq. 32 is applied as the current combustor is of LDI-2 concept. For the purpose of comparison, the emission of the LDI-1 concept is also calculated using Eq. 33 assuming same combustor parameters, both displayed in Table 13. The ICAO regulatory parameter $\mathrm{D}_{\mathrm{p}} / \mathrm{F}_{00}$ is also calculated using EINOx during the LTO cycle.

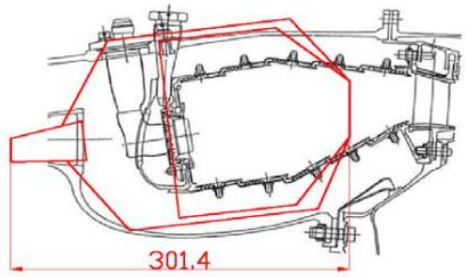

Figure 8 Comparison between design result and reference combustor
Table 13

Estimation of NOx emissions by correlations

\begin{tabular}{llllll} 
Type & \multicolumn{3}{c}{ EINOx (g NOx/kg fuel) } & \multicolumn{1}{c}{$\mathbf{D}_{\mathbf{p}} / \mathbf{F}_{00}$} \\
T/O (DP) & Climb & Approach & Idle & $(\mathbf{g} / \mathbf{k N})$ \\
LDI-1 & 17.9 & 12.7 & 2.5 & 0.4 & 25.3 \\
LDI-2 & 13.8 & 8.3 & 3.0 & 0.9 & 20.0
\end{tabular}

It is evident that the LDI-2 combustor produces less NOx than the LDI-1 at higher power settings. At the approach and idle condition, the NOx emission of LDI-2 is slightly higher, which can be interpreted by the assumption of the equivalence ratio applied in the NOx predicting equations. For LDI-1 correlation, the equivalence ratio in the primary zone includes the liner cooling air, while for LDI-2 calculation it refers to the local equivalence ratio at each stage without the liner air cooling. However, the value of $\mathrm{D}_{\mathrm{p}} / \mathrm{F}_{00}$ for LDI- 1 and LDI-2 is 25.3 and $20.0 \mathrm{~g} / \mathrm{kN}$ respectively, which implies that the LDI-2 combustor is more likely to produce lower NOx. By comparing the calculated NOx emissions index of the LDI combustors to the reference V2500 
engine combustors (see Figure 9), it is clear that the LDI combustor could achieve a much lower value than those of V2500 series RQL combustors. Finally, the $\mathrm{D}_{\mathrm{p}} / \mathrm{F}_{00}$ values are plotted on the CAEP regulation diagram (Figure 10). The V2500 RQL combustor is only able to fulfil the CAEP/6 standard, while the LDI combustor shows a reduction of $60 \%$ even $70 \%$ of the CAEP/6 emissions regulation. As the LDI technology is more matured and requirements in other aspects are met, the production in NOx may increase. With the TRL reaching higher, emission prediction correlations or higher fidelity models better describing the system will be needed for more accurate NOx prediction. Although the current values on NOx could be optimistic due to low TRL, the potential of LDI in achieving NOx emissions significantly lower than CAEP/6 is clearly shown.

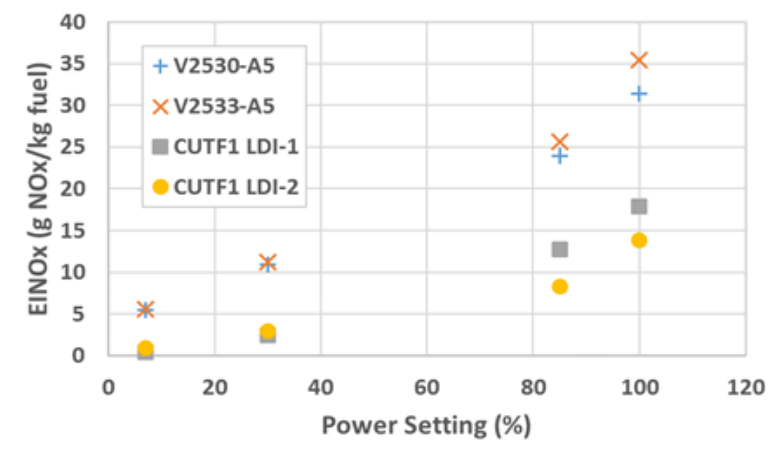

Figure 9 NOx emissions of LTO cycle

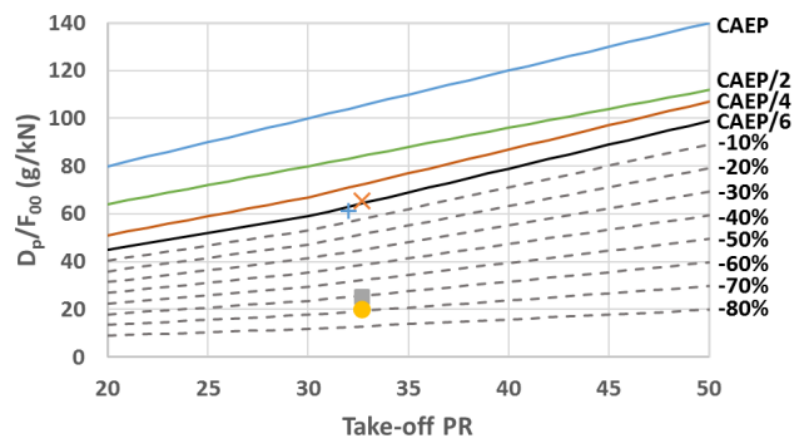

Figure 10 NOx emissions level of RQL combustors of V2500 engine and LDI combustors compared with CAEP standards

\subsection{SENSITIVITY STUDY}

A sensitivity study was conducted to analyse the impact of design assumptions and variables on the design output and NOx emissions, including gas properties, primary zone equivalence ratio, cooling air assigned to the dome and the primary zone, dome cooling air distribution, pilot equivalence ration at idle condition, fuel staging method during the approach and reference velocities of the dome and the passage; since no specific reference could be relied on during the selection of these assumed values. Through the investigation of the design uncertainties, the variables that are essential to the design could be identified, which would be an effective reference for future design refinement.

\begin{tabular}{|c|c|c|c|c|c|c|c|c|c|c|c|c|c|c|}
\hline & \multirow{2}{*}{$\begin{array}{c}\text { Air } \\
\text { distribution }\end{array}$} & \multicolumn{2}{|c|}{ Staging } & \multirow{2}{*}{$H E_{\text {dome }}$} & \multirow{2}{*}{$\mathrm{HE}_{\text {ref }}$} & \multirow{2}{*}{$\Delta \mathrm{P}_{\text {diff }} / \mathrm{P}_{3}$} & \multirow{2}{*}{$\mathrm{Y}$} & \multicolumn{2}{|c|}{$\mathrm{D}_{\mathrm{sw}}$} & \multicolumn{2}{|c|}{$\mathrm{S}_{\mathrm{N}}$} & \multicolumn{2}{|c|}{ EINOX } & \multirow{2}{*}{$D_{p} / F_{00}$} \\
\hline & & air & fuel & & & & & pilot & main & pilot & main & High & Low & \\
\hline $\begin{array}{c}\text { Gas properties } \\
\text { (Constant\&Variable) }\end{array}$ & - & - & - & ० & $\circ$ & $\bullet$ & - & - & - & - & - & - & - & - \\
\hline$\Phi_{P z}^{a}$ & $\circ$ & - & - & 0 & ० & o & 0 & - & - & - & - & $\bullet$ & $\circ$ & $\bullet$ \\
\hline $\begin{array}{l}\text { Fraction of liner cooling air } \\
\text { distributed to } \mathrm{PZ}{ }^{\mathrm{b}}\end{array}$ & $\circ$ & - & - & - & - & - & - & - & - & - & - & $\circ$ & - & $\circ$ \\
\hline Fraction of dome cooling ${ }^{c}$ & - & - & - & - & - & - & - & $\circ$ & - & - & - & - & - & - \\
\hline $\begin{array}{l}\text { Dome cooling air } \\
\text { distribution }\end{array}$ & - & $\bullet$ & - & - & - & - & - & $\circ$ & - & - & - & - & - & - \\
\hline$\Phi_{\text {pilot }}(\text { Idle condition })^{e}$ & - & $\bullet$ & $\bullet$ & - & - & - & - & $\bullet$ & - & $\circ$ & - & - & $\circ$ & - \\
\hline $\begin{array}{c}\text { Staging method } \\
\text { (Approach condition) }\end{array}$ & - & - & $\circ$ & - & - & - & - & - & - & - & - & - & $\circ$ & $\circ$ \\
\hline $\mathrm{V}_{\text {dome }}{ }^{f}$ & - & - & - & $\bullet$ & $\bullet$ & - & $\bullet$ & - & - & - & - & - & - & - \\
\hline$V_{\text {passage }}{ }^{g}$ & - & - & - & - & $\circ$ & - & - & - & - & - & - & - & - & - \\
\hline
\end{tabular}

Note: - - above 5\%; ○-1\%-5\%; - - below $1 \%$; a-range:0.500-0.518, $\Delta=0.006$; b-range:0.4-0.6, $\Delta=0.05$; c-range:0.10-0.15,

$\Delta=0.01$; d-range:0.16-0.28(pilot stage), $\Delta=0.03$; e-range: $1.2-2.4, \Delta=0.2 ;$ f-range: $7-12 \mathrm{~m} / \mathrm{s}, \Delta=1 \mathrm{~m} / \mathrm{s} ;$ g-range: $35-60 \mathrm{~m} / \mathrm{s}, \Delta=5 \mathrm{~m} / \mathrm{s}$;

Figure 11 Summary of the sensitivity study on design variables

The sensitivity study results are displayed in Figure 11. Each parameter varies in a range (range) with a variation interval $(\Delta)$ described using ( $a, b, c, d, e, f, g)$. According to the deviation from the values of the initial design, the level of their influence is classified as 'above 5\%', ' $1-5 \%$ ' and 'below 1\%'. Compared to constant gas properties, variable gas properties have high (above 5\%) influence on the diffuser pressure loss, especially dump diffuser loss mainly due to changes in gas isentropic coefficient and density leading to a smaller reference area. The primary zone equivalence ratio is critical to the flame temperature and the fraction of dilution air, which greatly affects NOx emissions during take-off and climb. The effect of the fraction of liner cooling air assigned to the primary zone is visible while not significant, so is that of the cooling air in the dome. However, the variation in the distribution of the cooling air in each stage of the dome results in more than 5\% fluctuation in pilot air staging in order to maintain constant local equivalence ratio. At idle condition, the operability of the 
combustor depends on the equivalence ratio of the pilot stage, and the air staging varies accordingly at design point since the air needed in the pilot zone is reduced while the primary zone air is fixed. The fuel staging changes consequently in order to maintain constant equivalence ratio. The swirler dimensions are also affected due to the variation in air staging, especially those of pilot swirlers. During the approach, only the pilot and main1 stage (2-stages) are lit for the initial design while a different staging method can be applied. It can be seen that 3-stages with equal or unequal equivalence ratio at approach condition does not differ notably to the 2-stage method. The impact of dome velocity on the combustor dome and reference height is apparent since the air mass flow entering the dome is invariant. The penetration of the dilution holes varies significantly as a consequence. The effect of the passage velocity is not as evident compared to that of the dome velocity, since the fraction of the passage air is relatively small. It reveals the fact that the dome design is more definitive for LDI combustors.

\subsection{CONCLUSION}

This paper presents the development of a preliminary aerodynamic design method for LDI combustors with reference to conventional combustor design method, covering combustor sizing, fuel and air staging and component design of the diffuser, swirlers and liner holes. The calculation of major combustor performance parameters such as air distribution, pressure loss, combustor size and NOx emission level are integrated in the developed codes.

A case study was conducted through the design of CULDI2015, an LDI combustor with the input geometry and boundary conditions obtained from the RQL combustor of the V2500 series engine. The designed combustor is compared to the original RQL combustor, demonstrating a length reduction of $18 \%$ together with a potential NOx reduction by $70 \%$ with regard to CAEP/6 regulation. In the sensitivity study, several uncertain design assumptions and variables are investigated. The major impact of these parameters on the design output was identified and analysed, including the effect of gas properties on the diffuser pressure loss, the primary zone equivalence ratio on the NOx emission, the dome cooling air distribution on the air staging, the pilot zone equivalence ratio on the fuel and air staging as well as the pilot swirler size and the dome velocity on the combustor size.

Although the designed LDI combustor seems reasonable for the preliminary design, it could be further improved. Due to the lack of material on LDI combustor applications, the codes should be validated and improved once the LDI is mounted on a real engine producing experimental data. Additionally, design methods for other types of LDI combustors such as NEWAC LDI, LDI-1 and LDI-2 Goodrich's concept could also be incorporated so that the codes can be applied and verified to a wider range. The current design results can be used as the geometrical input and boundary conditions for higher fidelity simulations such as CFD, which will provide feedback to the preliminary design codes with more precise information so that it can be further improved.

\section{ACKNOWLEDGMENTS}

The authors would like to thank Yating Zhao for providing the engine performance simulation data of the V2500 engine as the reference values. Jie Li is also grateful for the AECC Shenyang Engine Research Institute to fund her study at Cranfield University, UK, where she conducted this research. The authors would also like to express appreciation to Dr. Eric Goodger for kindly proofreading the paper as well as the publication officer and reviewers for their reviews and comments.

\section{REFERENCES}

[1] M Foust, D Thomsen, D Stickles, C CoOper and W DodDs, "Development of the GE Aviation Low Emissions TAPS Combustor for Next Generation Aircraft Engines," in 50th AIAA Aerospace Sciences Meeting including the New Horizons Forum and Aerospace Exposition, Nashville, Tennessee, 2012.

[2] S ColantuOni, "Sub-project 6 innovative combustor," Presented at European Engine Technology, June, 2009.

[3] D R REDDY and C LEE, "An overview of low-emission combustion research at NASA Glenn," in Proceedings of ASME Turbo Expo 2016: Turbomachinery Technical Conference and, Seoul, South Korea, 2016.

[4] H MongIA, “TAPS: A Fourth Generation Propulsion Combustor Technology for Low Emissions," in AIAA 
International Air and Space Symposium and Exposition: The Next 100 Years, Dayton, Ohio, 2003.

[5] H KLINGER, W LAZIK and T Wunderlich, "The engine 3E core engine," ASME Turbo Expo 2008: Power for Land, Sea, and Air, pp. 93--102, 2008.

[6] R TACINA, C MAO and C Wey, "Experimental investigation of a multiplex fuel injector module with discrete jet swirlers for low emission combustors," AIAA Paper, vol. 135, 2004.

[7] K M Tacina, C T Chang, Z J He, P Lee, B Dam and H C Mongia, "A second generation swirl-venturi lean direct injection combustion concept," AIAA paper, vol. 3434, 2014.

[8] A M MELLOR, Design of modern turbine combustors, Academic Pr, 1990.

[9] J D MatTingly, Aircraft engine design, American Institute of Aeronautics and Astronautics, 2002.

[10] P P WALSH and P FLETCHER, Gas turbine performance, John Wiley \& Sons, 2004.

[11] Y ZHAO, Preliminary aerodynamic desin of Rich-burn Quick-quench Lean-burn combustor for civil transport aircraft engine, MSc thesis. Cranfield University, UK, 2015.

[12] A H LefebVRe, Gas Turbine Combustion, CRC Press, 1998.

[13] B S MOHAMMAD and S M JENG, "Design procedures and a developed computer code for preliminary single annular combustor design," AIAA paper, vol. 5208, 2009.

[14] A H LeFEBVRE and D R BALLAL, Gas turbine combustion, CRC Press, 2010.

[15] J M BÉER and N A ChIGIER, Combustion aerodynamics, Krieger Publishing Company, 1972.

[16] S J GLASS, The effect of primary zone swirler aerodynamics on spray, MSc thesis. Cranfield University, UK, 1989.

[17] K M LeE, C M TACINA and C Wey, "NASA Glenn High Pressure Low NOx Emissions Research," NASA TM-2008-214974, 2008.

[18] R TACINA, C Wey, P LIANG and A Mansour, "A low-NOx Lean-Direct Injection, multiPoint integrated module combustor concept for advanced aircraft gas turbines," NASA/TM-2002-211347, 2005.

[19] J CAI, S M JENG and R TACINA, "The structure of a swirl-stabilized reacting spray issued from an axial swirler," 43 rd AIAA Aerospace Sciences Meeting and Exhibit, 2005.

[20] Y FU and S M JENG, "Experimental investigation of swirling air flows in a multipoint LDI combustor," AIAA, vol. 5685, p. 43, 2007.

[21] S L YANG, Y K SIOW, B D PESCHKE and R R TACINA, "Numerical study of nonreacting gas turbine combustor swirl flow using Reynolds stress model," Journal of engineering for gas turbines and power, vol. 125, pp. 804-811, 2003.

[22] J CAI, Aerodynamics of lean direct injection combustor with multi-swirler arrays, $\mathrm{PhD}$ thesis. University of Cincinnati, 2006.

[23] Y FU, S M JENG and R R TACINA, "Characteristics of the swirling flow in a multipoint LDI combustor," 45th AIAA Aerospace Sciences Meeting and Exhibit, p. 846, 2007.

[24] K AJMAni, H Mongia and P LeE, "CFD Computations of Emissions for LDI-2 Combustors with Simplex and Airblast Injectors," AIAA paper, vol. 3529, 2014.

[25] R M HERNANDEZ, "V2500 general familiarisation," [Online]. Available: http://www.slideshare.net/RafaelHernandezM/v2500-gf-issue-01. [Accessed July 2015]. 
2017-06-21

Preliminary aerodynamic design

methodology for aero engine lean direct injection combustors

Sun, Xiaoxiao

Cambridge University Press

Jie Li, Xiaoxiao Sun, Yize Liu and Vishal Sethi, Preliminary aerodynamic design methodology for aero engine lean direct injection combustors, Aeronautical Journal, Vol. 121, Issue 1242, August 2017, pp. 1087-1108

http//dx.doi.org/10.1017/aer.2017.47

Downloaded from Cranfield Library Services E-Repository 